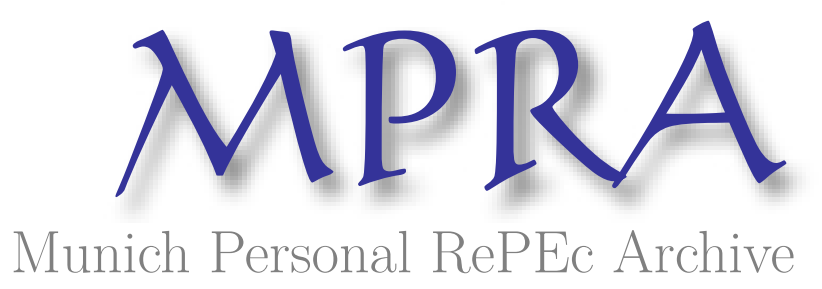

\title{
Amazon Mechanical Turk Workers Can Provide Consistent and Economically Meaningful Data
}

Johnson, David and Ryan, John

University of Central Missouri

12 July 2018

Online at https://mpra.ub.uni-muenchen.de/88450/

MPRA Paper No. 88450, posted 21 Aug 2018 10:20 UTC 


\title{
Amazon Mechanical Turk Workers Can Provide Consistent and Economically Meaningful Data
}

\author{
David Johnson* \\ University of Central Missouri \\ John Barry Ryan ${ }^{\dagger}$ \\ Stony Brook University
}

July 12, 2018

\begin{abstract}
We explore the consistency of the characteristics of individuals who participate in studies posted on Amazon Mechanical Turk (AMT). The primary individuals analyzed in this study are subjects who participated in at least two of eleven experiments that were run on AMT between September of 2012 to January of 2018. We demonstrate subjects consistently report a series of demographic and personality characteristics. Further, subjective willingness to take risk is found to be significantly correlated with decisions made in a simple lottery experiment with real stakes - even when the subjective risk measure is reported months, sometimes years, in the past. This suggests the quality of data obtained via AMT is not significantly harmed by the lack of control over the conditions under which the responses are recorded.
\end{abstract}

*Department of Economics and Finance, University of Central Missouri, Warrensburg, MO 64093, U.S.A. Telephone: 1-336-639-2190. Email: djohnson@ucmo.edu

${ }^{\dagger}$ Department of Political Science, Stony Brook University, Stony Brook, NY 11794, U.S.A. Email: john.ryan@stonybrook.edu 


\section{Introduction}

Amazon Mechanical Turk (also known as AMT or MTurk) has become an increasingly common tool for researchers in social sciences (e.g., Clifford, 2014; Verkoeijen and Bouwmeester, 2014; Milita et al., 2017). This is partly because researchers are looking for experimental samples that are more heterogeneous than student samples and cheaper than samples recruited by survey firms. However, critics of AMT worry that the results of studies using AMT are unreliable and not economically meaningful. The reasoning behind such worries are often based off of some mixture of formal criticisms (e.g., frequency of participation and unrepresentative samples) that are discussed in the academic literature (c.f., Krupnikov and Levine, 2014; Huff and Tingley, 2015), and informal criticisms that crop up in referee reports (e.g., loss of experimental control, low incentives, and overall subject quality). Given that experiments performed on AMT generally replicate the results from studies on nationally representative samples (Mullinix et al., 2015) and laboratory studies (Horton et al., 2011), these criticisms - particularly, the informal flavor - seem puzzling.

Naturally the observation of poor quality responses could be the result of rational decision making on the part of the respondent. For example, it is easy to imagine that some respondents may (or may not) have beliefs/preferences that align with a study's goals. If the study's goals are deciphered by the respondent, the respondent could answer questions in a manner to achieve or undermine the study's goals rather than responding honestly. Additionally, because respondents are paid for each survey they complete, there is the incentive to complete surveys as quickly as possible. For instance, if a respondent has 10 minutes to complete an online survey and mindlessly completes the 10 minute survey in 5 minutes, they are free to complete another survey and will get paid for both. Hence, regardless of whether respondents are carefully reading the questions or carelessly responding, they might give poor quality responses.

In this paper, we add to the growing body of literature reporting the efficacy of the 
platform by demonstrating that AMT worker responses are consistent across time and correlated, in the expected direction, with decisions that are made when there are real stakes present. Our data is from eleven different experiments run on AMT from September of 2012 to January of 2018. In each of these experiments, we collected at least two of the following measures: age, gender, impulsivity, and subjective willingness to take risk. We take advantage of the fact that AMT data sets report workers' anonymous "worker id" numbers and use this information to track worker responses over time. We show differences in responses are small - which would be consistent with measurement error - both to single questions and a multi-item index. ${ }^{1}$ Further, we demonstrate that self-reported risk measures are highly correlated with a financially incentivized measure of risk. This is important because it suggests the consistency is economically meaningful and not the result of some decision rule used to complete surveys more quickly - for example, always picking the first option. Because we can predict the respondent's incentivized behavior with self-reported measures taken at the same time or months or, in some cases, even years before, this suggests AMT respondents provide valid measures of variables that are important to social scientists.

\section{$2 \quad$ AMT and Inconsistent Responses}

AMT is an online labor market made up of workers (respondents/subjects) and requestors (researchers). Requestors on AMT post human intelligence tasks (HITs) that are then completed by workers in exchange for payment. In the social sciences, these HITs are often experiments (e.g., Clifford and Gaskins, 2016; Del Ponte et al., 2017; Milita et al., 2017) and are seen as an alternative to laboratory experiments that use student samples (Goodman et al., 2013). Each HIT on AMT pays workers a fixed participation fee for completing a HIT. These fixed participation fees are typically quite small and range from $\$ 0.05$ to

\footnotetext{
${ }^{1}$ In fact, the responses to the question about risk preference are more reliable than responses to one of the long-running panel survey.
} 
$\$ 1.00$. This participation fee is analogous to the show-up payments paid to subjects in laboratory economics experiments. Requestors also have the option of paying workers a bonus. A convenient feature of these bonuses is that they are individually assigned after the requestor has observed workers' responses. This means requestors can observe workers' behaviors/decisions and pay them based off of their observed behavior/decisions. Like the participation fees, these bonuses are quite small relative to laboratory payments.

Demographically, AMT workers are significantly more varied than university subject pools (Ipeirotis, 2010; Buhrmester et al., 2011; Behrend et al., 2011). For example, it is common to observe workers who report to be as young as 18 and as old as 65. However, American workers are still younger and more ideologically liberal than the overall U.S. population (Berinsky et al., 2012). More importantly, for the purposes of this paper and others using AMT, American workers on AMT generally have a lower reported income (c.f., Paolacci et al., 2010; Berinsky et al., 2012; Levay et al., 2016) are more likely to report to be unemployed (e.g., Ipeirotis, 2010; Goodman et al., 2016).

This suggests that the money earned from completing HITs might be especially valuable to AMT workers. Since the HITs generally pay small amounts, the only way to earn even minimum wage is to complete many HITs. However, this could lead to poor responses as respondents engage in satisficing or some quick decision rule (for example, always choose the middle category). It could also lead to response instability, one of the most common issues in social science surveys (Converse, n.d.). Zaller (1992) notes that one way to cure response instability is to encourage respondents to "stop and think" prior to answering. For these AMT respondents, stopping to think is costly as time spent thinking is time not spent earning money for completing another HIT.

At the same time, survey experiments conducted on the platform have been shown to replicate the results from surveys on representative samples (Berinsky et al., 2012; Mullinix et al., 2015).Yet, this does not necessarily mean that AMT responses are high quality. Ex- 
perimental effects would potentially replicate if responses in both samples were of poor quality. AMT workers have a financial incentive to finish quickly, but respondents to a more traditional survey also would want to finish quickly.

As part of an effort to improve the quality of responses, experimental economists ask respondents to participate in tasks with real stakes in order to measure underlying attitudes. For example, one could measure intergroup affect with survey questions, but measuring affect via a trust or dictator games avoids issues of social desirability (Fowler and Kam, 2007; Carlin and Love, 2013). By offering real stakes to answer a question, researchers can incentivize careful responding. An AMT worker, who answers the real stakes question too quickly, risks lower earnings which may defeat the purpose of quick responding. However, one could argue that the cost of this behavior is mitigated by the relatively low stakes. Hence, to demonstrate that AMT workers provide quality data, we need to demonstrate both that the responses are consistent across time, but also that the measures obtained via survey questions are consistent with those from a real (but low) stakes task.

\section{Data}

We ask two central questions: 1) is the data provided by AMT workers consistent? and 2) if so, are workers' responses economically meaningful - i.e., do their responses to survey questions correlate with their performance in a real stakes task? The data we use is from eleven different experiments which were run from 2012 to 2018. To avoid selection bias, we use data from all of the experiments author one has run on AMT that asked workers to report at least two of the measures above and have access to their worker identification number (workerid) and the date the experiment was posted. ${ }^{2}$ The dates of the experiments

\footnotetext{
${ }^{2}$ A description of each experiment is found in Appendix section 5. All experimental data is posted online. We will update the data set as we run more experiments.
} 
and the number of observations in each experiment are found in Table E.1 in the Appendix. The timing of each of the variables of interest (e.g., age and impulsiveness test) varies widely across experiments. For example, in some experiments workers were asked about their willingness to take risk prior to the experiment (to conceal a treatment assignment variable) and, in others, the question occurred after the main experiment.

\subsection{Questions}

In assessing the consistency of workers' responses we evaluate four variables. The first two are basic demographic variables: age and gender. These measures provide only a lowbar test as answering those questions quickly and carelessly would take about as long as answering the questions accurately. It will serve to demonstrate that AMT workers are not "trolling" researchers (Lopez and Hillygus, 2018).

We perform more comprehensive analyses of two respondent personality traits: impulsiveness and willingness to take risk. Impulsiveness is a commonly studied trait in the psychology of criminals (Farrington, 1998) and has been used in political science to explain differences between liberals and conservatives (McAdams et al., 2013), partisan strength (Hatemi et al., 2009) and political violence (McDermott et al., 2013). Impulsiveness is measured using the Barratt Impulsivity Test (Stanford et al., 2009). Respondents indicate how often they engage in thirty different activities (e.g., "I plan tasks carefully") using a four point scale ranging from "Rarely/Never" (1) to "Almost Always/Always" (4). A worker's impulsiveness score is the sum of their responses. ${ }^{3}$ To demonstrate that workers consistently report their level of impulsiveness, we use both workers' responses to each of the impulsiveness questions as well as their total score on the instrument.

Willingness to take risk is measured using the general risk attitudes question from the German Socio-Economic Panel Survey (SOEP) which was popularized in Dohmen et al.

\footnotetext{
${ }^{3}$ Some of these questions are reverse coded.
} 
(2011). The English translation of the question is as follows:

How do you see yourself: Are you generally a person who is fully prepared to take risks or do you try to avoid taking risks?

Workers answer this question on an 11 point scale ranging from 0 to 10 - with 0 corresponding to "I avoid risk" and 10 corresponding to "Fully prepared to take risks."

Additionally, in two of the experiments respondents were asked to choose to play one lottery from a list of several lotteries; this is a common way to measure an individual's risk profile in experimental economics (e.g., Holt and Laury, 2002; Dave et al., 2010). We will explain the details of the real stakes task later when we examine how it correlates with the answer to the SOEP risk attitudes question.

A convenient feature of the data sets generated using AMT is that they not only include workers' decisions and responses but also a unique randomly generated worker identification number (workerid) and the date at which the HIT was posted online. We use the workerid to link the responses of workers who participated in at least two of the experiments presented in Table E. 1 in the Appendix. The date is used to establish the order of the responses - allowing us to compare a respondent's first response to their future responses.

\subsection{AMT Workers}

In the eleven experiments, there are 5,347 observations. 3,566 workers completed a single experiment. 730 workers completed at least two, and 223 workers completed three or more experiments. The average number of experiments completed by workers is 1.24 and the most experiments completed by a worker is eight. We did not contact workers who participated in one study to participate in future studies. Hence, the fact that respondents appear in this study in a panel nature is purely by chance. 4,127 workers reported their gender, 2,829 reported their age, 3,811 reported their willingness to take risk, and 2,730 
completed the Barratt Impulsivity Test. ${ }^{4}$

Table 1 presents the summary statistics of the workers who participated in the experiments. ${ }^{5}$ Each variable in Table 1 contains subscripts indicating a group and a response time. The first subscript corresponds to the order of the workers' response (i.e., 1 if first; 2 if last). Workers are classified into one of two groups. The first group (group 1) are workers who participated in one experiment. The second group (group 2) are workers who participated in two or more experiments. The group is indicated by the second subscript (i.e., 1 if group 1; 2 if group 2). For example, Risk ${ }_{1,2}$ is the average earliest reported willingness to take risk for workers who completed more than one experiment.

The distributions of Age, Risk, and IMP by group, and order of response are found in Figure 4. Figure 4 and Table 1 suggest that there are differences in the workers who completed more than one experiment compared to those who only completed a single experiment. Workers who completed more than one experiment are significantly more likely to report being male (test of proportions: 0.561 vs $0.628, p=0.001$ ), are less impulsive (t-test: 60.623 vs $58.329, p<0.001$; u-test: $p<0.001$ ), are less willing to take risk (t-test: 5.364 vs 5.037, $p=0.005$; u-test: $p=0.005$ ), and older (t-test: 32.149 vs 33.856, $p<0.001$; u-test: $p<0.001$ ) than workers who completed a single experiment. ${ }^{6}$ This means the experienced AMT participants have somewhat different characteristics than those who are less experienced, which may lead to questions regarding external validity relating to the consistency of responses. Yet, it does not affect our ability to test whether

\footnotetext{
${ }^{4} \mathrm{~A}$ breakdown of average responses by the day of the week the batch of the HIT is posted is found in section 1 of the Appendix. Detailed analysis of "day of the week" effects are not the primary purpose of this paper but is available upon request.

${ }^{5}$ Careful readers will note that the sum of the variables in Table 1 do not add up to the "correct" total. This is due to the fact that workers could have completed experiments that did not ask them to report one or two of the measures. So, for example, while a worker could have completed more than one experiment, she could have actually only reported her age once.

${ }^{6}$ All t-tests assume unequal variance.
} 
Table 1: Summary Statistics

\begin{tabular}{cccccc}
\hline \multicolumn{7}{c}{ Responded Once } \\
Variable & Obs & Mean & Std. & Min & Max \\
\hline \hline Male $_{1,1}$ & 3398 & 0.561 & 0.496 & 0 & 1 \\
Age $_{1,1}$ & 2136 & 32.149 & 10.028 & 6 & 69 \\
Risk $_{1,1}$ & 3090 & 5.364 & 2.691 & 0 & 10 \\
$\mathrm{IMP}_{1,1}$ & 2055 & 60.623 & 11.628 & 30 & 110 \\
\hline \multicolumn{7}{c}{ Responded More than Once (First Response) } \\
Variable & Obs & Mean & Std. & Min & Max \\
\hline \hline Male $_{1,2}$ & 678 & 0.645 & 0.479 & 0 & 1 \\
Age $_{1,2}$ & 418 & 33.117 & 9.536 & 18 & 67 \\
Risk $_{1,2}$ & 553 & 4.911 & 2.793 & 0 & 10 \\
$\mathrm{IMP}_{1,2}$ & 406 & 58.628 & 11.106 & 32 & 92 \\
\hline
\end{tabular}

Responded More than Once (Last Response)

\begin{tabular}{cccccc} 
Variable & Obs & Mean & Std. & Min & Max \\
\hline \hline Male $_{2,2}$ & 678 & 0.639 & 0.481 & 0 & 1 \\
Age $_{2,2}$ & 418 & 33.969 & 9.663 & 19 & 69 \\
Risk $_{2,2}$ & 553 & 4.929 & 2.824 & 0 & 10 \\
IMP $_{2,2}$ & 406 & 58.369 & 12.441 & 31 & 120 \\
\hline
\end{tabular}

Summary statistics of variables of interest by group and order of response. Male is the reported gender ( 1 if male; 0 if female). IMP is Barratt Impulsiveness Test score. Risk is general willingness to take risk. Age is reported age in years. First subscript number indicates whether this is for a respondent's first (1) or most recent response (2). Second subscript number indicates whether the respondent participated in only one survey (1) or at least two experiments (2). 
experienced and inexperienced workers provide economically meaningful responses. ${ }^{7}$

In the coming analysis, we will primarily consider the respondents who participated in more than one study as those are the only respondents who we can show are consistent in their responses. However, we will later use some participants who participated only once to compare their responses to the risk question to their decisions made in the real stakes lottery task. As we will demonstrate, the relationship between subjective risk preferences and choices made in the incentivized lottery experiment, for workers who participated in only one experiment, is not qualitatively different than the relationship observed in workers who participated in more than one experiment.

\section{Results}

\subsection{Age and Gender Consistency}

As a "low-bar" test of the consistency of responses, we start by exploring workers' first reported gender and age and compare these responses to their final responses. The average number of days between first reported gender(age) and last reported gender(age) is 401 (289) days. Overall, 666 workers consistently reported their gender. 237 of these workers reported being female and 429 of these workers reported being male. Eight(four) workers first reported being male(female) but reported being female(male) in the last experiment they completed. Thus, workers consistently report their gender $98.23 \%$ of the time. $^{8}$

\footnotetext{
${ }^{7}$ Note that the averages presented in Table 1 do not match the averages and proportions reported when we are comparing responses across groups. This is not a mistake but reflects the fact not all HITs asked the same questions. See Footnote 5 for a more concrete example.

${ }^{8}$ Given that recent studies estimate that between $0.4 \%$ and $0.6 \%$ of the US population identifies as transgender (Flores et al., 2016), some of the observed inconsistency possibly represents real changes in gender identities rather than a mistake or careless response. Evidence in support of this can be seen when looking at the workers who participated in more than one experiment and changed their reported gender. For example, one worker, first re-
} 
Figure 1: Distribution of workers' characteristics by group and completion order.

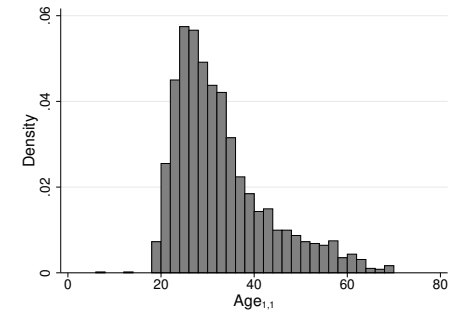

(a) Distribution of Age $_{1,1}$

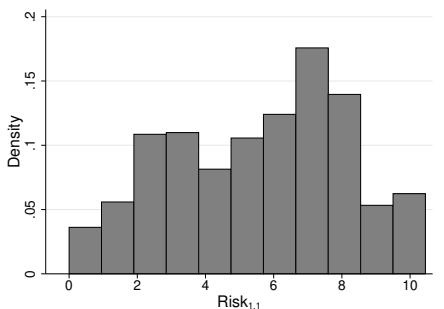

(d) Distribution of Risk 1,1

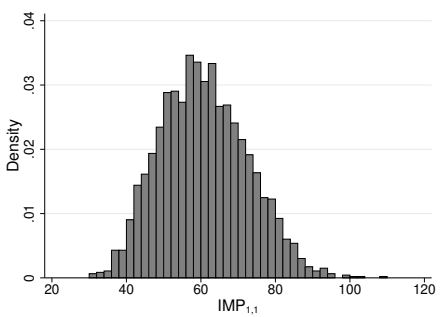

(g) Distribution of $\operatorname{IMP}_{1,1}$

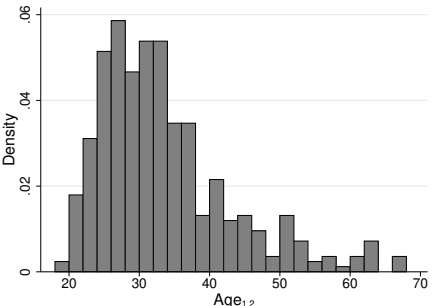

(b) Distribution of Age $_{1,2}$

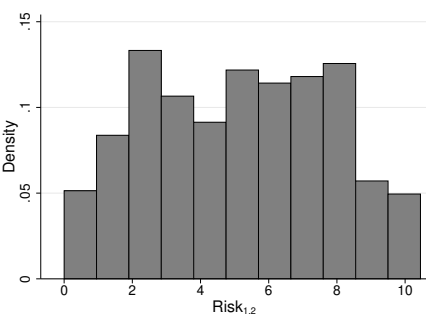

(e) Distribution of Risk 1,2

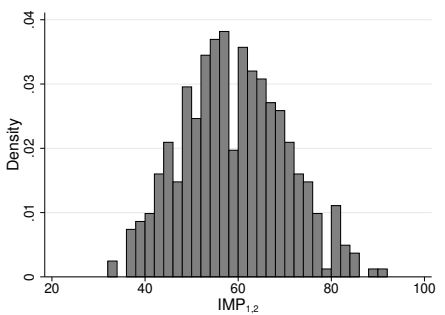

(h) Distribution of $\operatorname{IMP}_{1,2}$

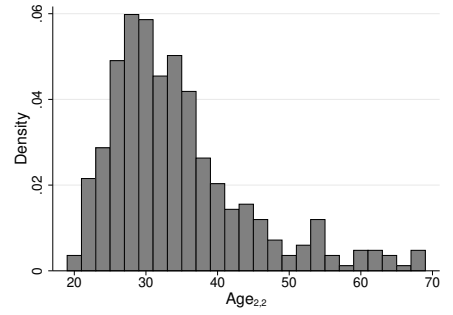

(c) Distribution of Age $_{2,2}$

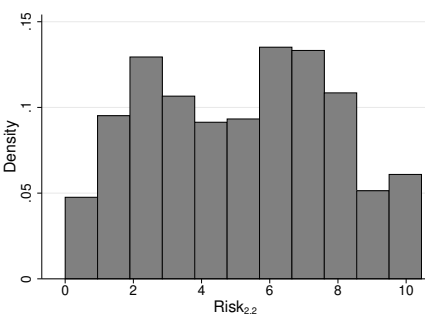

(f) Distribution of Risk ${ }_{2,2}$

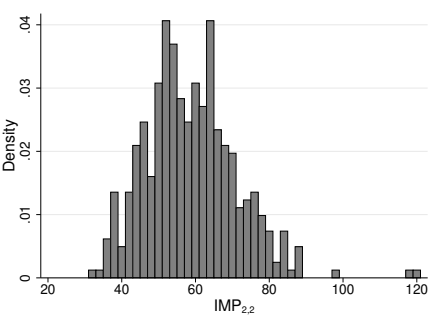

(i) Distribution of $\mathrm{IMP}_{2,2}$

First row of sub-figures in Figure 4 corresponds to age, second row corresponds to reported willingness to take risk, and the third row is Impulsivity Test scores. First column are the distributions of characteristics of the workers who only participated once (group 1). Middle column are the distributions of characteristics reported in the first experiment among workers who participated in two or more of the experiments (group 2). Third column are the distributions of characteristics reported in the last experiment completed among those who completed more than one experiment (group 2). 
418 workers reported their age more than once. The correlation between first and last reported age is positive and significant $(r=0.977, p<0.0001)$. The average reported age when workers completed their first(last) experiment 33.12(33.97) which translates into a difference of .85 years. While this difference is statistically significantly different from zero (t-test: $p<0.001$ ) it is expected considering workers will age over the time between experiments. Yet, this difference is not statistically different from the difference in the time they last reported their age and first reported their age divided by 365 (t-test: 0.85 vs .793, $p=0.174$ ). Just as with gender there is some inconsistency. There are eight "Benjamin Buttons" who got younger and five workers who aged more than was possible. ${ }^{9}$ Overall, these results suggest, for simple demographic questions at least, MTurk respondents are fairly consistent.

\subsection{Consistency in Impulsivity}

We now present results suggesting that workers are consistently reporting their impulsivity. The distribution of the absolute difference between workers' first and last Impulsiveness Test score is found in Figure 2a. In Figure 2b, we present a scatter plot of $\operatorname{IMP}_{1,2}$ and $\mathrm{IMP}_{2,2}$. The average time difference between workers' first and last Impulsivity Test is 339 days. As with the previous demographics and characteristics, workers consistently report their impulsivity.

The difference in workers' first and last Impulsivity Test score is not statistically different (paired t-test: 58.628 vs $58.369, p=0.5843$ ). While the two scores are highly correlated $(r=0.679, p<0.001)$ the observed correlation is not as high as what is re-

ported being male and then subsequently reported being female in two later experiments. Obviously, it is impossible to say whether or not the first response given by this worker was a mistake or not but it is noteworthy to mention that this worker was very consistent in their reported willingness to take risk $\left(\right.$ Risk $_{1,2}=4$ and Risk $\left._{2,2}=5\right)$ and impulsiveness $\left(\operatorname{IMP}_{1,2}=52\right.$ and $\mathrm{IMP}_{2,2}=49$ ).

${ }^{9}$ For example, one worker aged 17 years over 163 days. 
Figure 2: Distribution of the Absolute Differences and Scatter Plots of First and Last Impulsivity Test Responses.

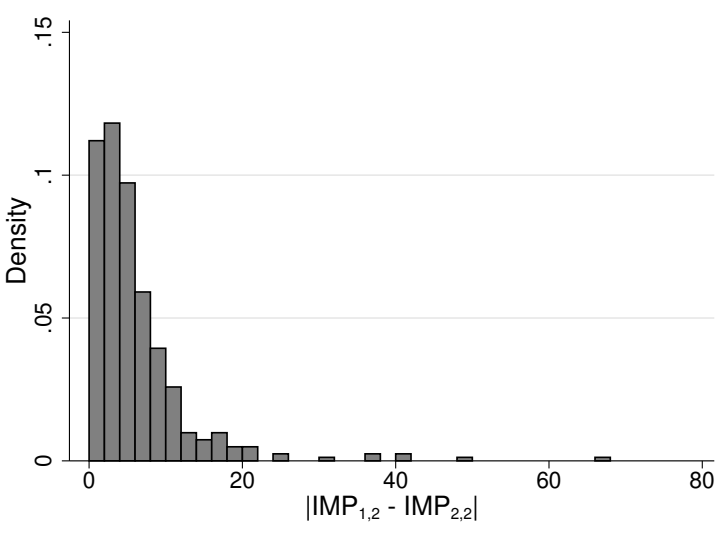

(a) Distribution of $\left|\mathrm{IMP}_{1,2}-\mathrm{IMP}_{2,2}\right|$

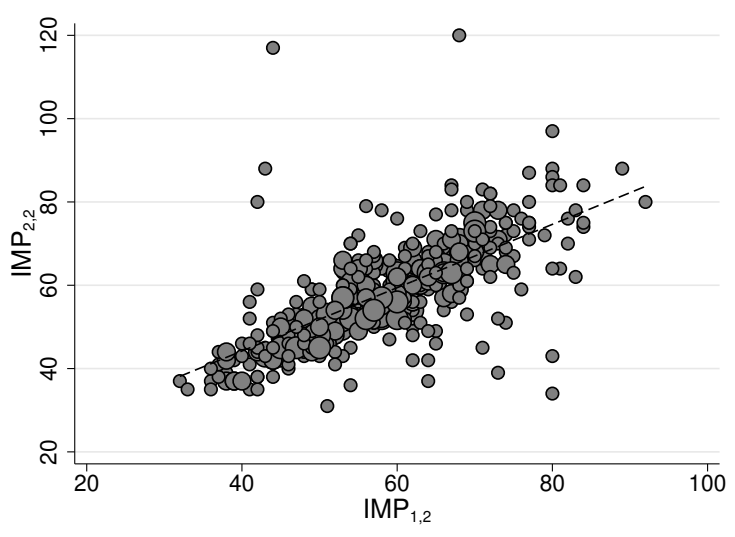

(b) Scatter Plot of $\operatorname{IMP}_{1,2}$ and $\operatorname{IMP}_{2,2}$

Figure 2a presents the distribution of the absolute difference of workers' first Impulsiveness Test score and final Impulsiveness Test score. Figure $2 b$ presents a scatter plot of workers' first Impulsiveness Test score $\left(I M P_{1,2}\right)$ and final reported willingness to take risk $\left(I M P_{2,2}\right)$. X-axis corresponds to first reported willingness to take risk/test score while y-axis is final reported willingness to take risk/test score. Dashed lines are fitted regression lines. Dot sizes, in the scatter plots, indicate the proportion of responses.

ported in Stanford et al. (2009) who finds a one month correlation across test scores of 0.83. As can be seen in Figure 2a, this difference is being driven by a few very inconsistent workers. For example, if we remove the eight most inconsistent workers (or less than $2 \%$ of the sample of workers who completed the Impulsivity Test more than once), $r$ increases to $.804 .^{10}$

The number of days between measures does not affect the consistency of the responses. This can be seen in Figure 3 which plots the absolute difference between first and last scores on the impulsivity measure on the y-axis and the number of days between responses on the $\mathrm{x}$-axis. When we estimate an OLS model using the absolute difference as a dependent variable and the number of days between responses as the independent

\footnotetext{
${ }^{10}$ Interestingly, one of these workers inconsistently reported their gender which might suggest this an extreme troll.
} 
Figure 3: Difference in Impulsivity Test Responses Over Time.

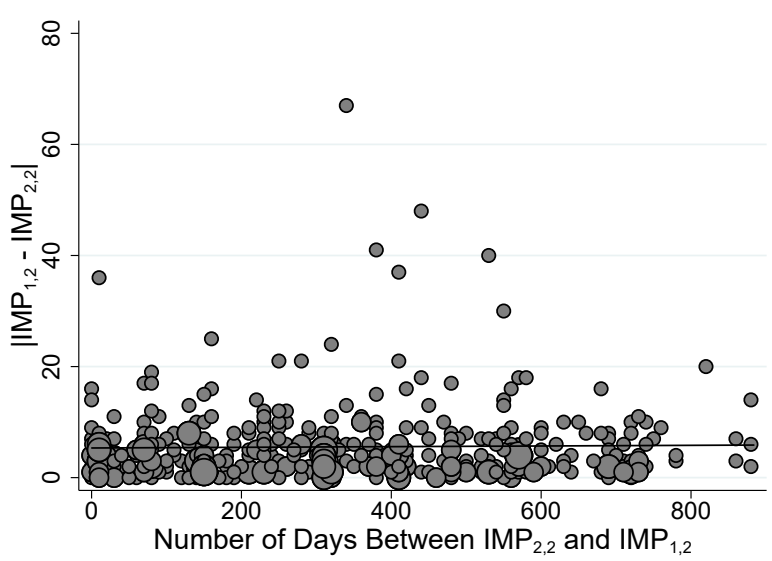

The solid lines is the fitted regression line. Dot sizes indicate the proportion of responses.

variable, we find the coefficient on the number of days between measures is small and not statistically significant $($ coef $=0.001, p=0.594, n=406)$.

In Appendix section 4, we present the result for each of thirty items in test. The difference between initial and final responses to one item has a p-value less than 0.05 with another two items having p-values less than 0.1. Given the multiple tests, we should adjust our p-values for multiple comparisons. Whether we account for "false discovery rate" - the expected proportion of false positives (Type I errors) (Benjamini and Hochberg, 1995) - or "Family-Wise Error Rate" - the probability of incorrectly rejecting even one null hypothesis - using the common Bonferroni correction, there are no statistically significant differences between the first and final responses to any of the items.

\subsection{Consistency in Willingness to Take Risk}

The distribution of the absolute difference between workers' first and last reported willingness to take risk is found in Figure 4a. In Figure 4b, we present a scatter plot of Risk ${ }_{1,2}$ and $\mathrm{Risk}_{2,2}$. The average time difference between workers' first and last response to the risk question is 418 days. The difference between reported willingness to take risk the first and 
Figure 4: Distribution of the Absolute Differences and Scatter Plots of First and Last Impulsivity Test Responses.

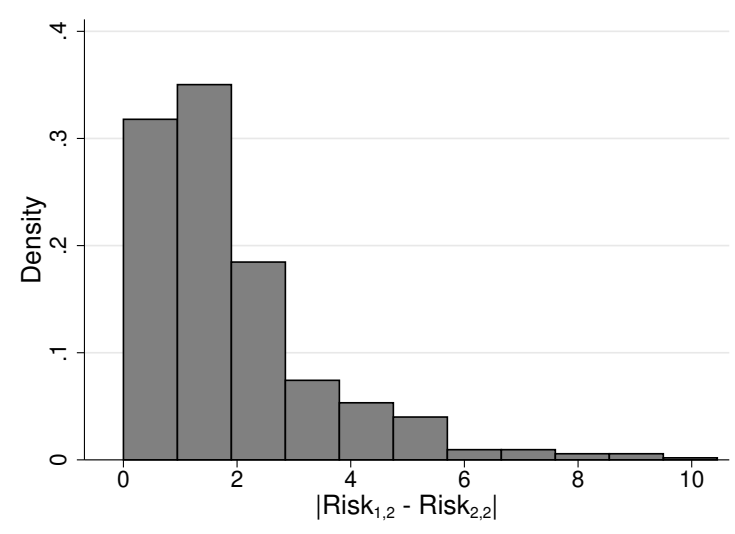

(a) Distribution of $\mid$ Risk $_{1,2}$-Risk $2,2 \mid$

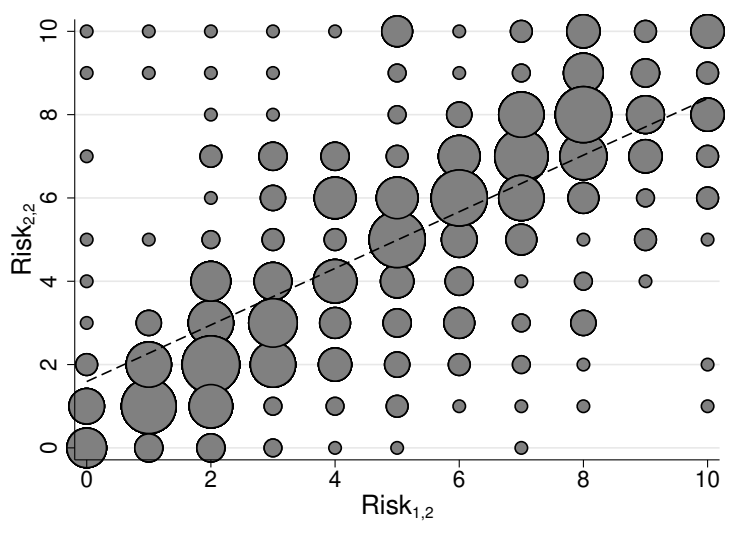

(b) Scatter Plot of Risk ${ }_{1,2}$ and Risk 2,2

Figure 4 a presents the distribution of the absolute difference of workers' first reported general willingness to take risk and final reported general willingness to take risk. Figure $4 \mathrm{~b}$ presents a scatter plot of workers' first reported willingness to take risk (Risk ${ }_{1,2}$ ) and final reported willingness to take risk (Risk ${ }_{2,2}$ ). Dashed lines are fitted regression lines. Dot sizes, in the scatter plots, indicate the proportion of responses.

last time they completed an experiment is not statistically significant (paired t-test: 4.911 vs 4.929, $p=0.852$ ) and, as expected, the responses themselves are highly correlated ( $r=0.672, p<0.001)$. Further, the reported reliability (i.e., test and re-test correlation) is higher than the 30-49 day reliability $(r=0.60)$ reported in the SOEP manual (Richter et al., 2017).

Additionally, we once again see no evidence that the difference in reported willingness to take risk increases in the number of days between the first and last time it is reported. We show this in Figure 5 which plots the absolute difference between first and last responses to risk question on the $\mathrm{y}$-axis and the number of days between responses on the $\mathrm{x}$-axis. When estimating the absolute difference between first and last response, with OLS, using the number of days between responses as the independent variable, we find the coefficient on the number of days between measures to be small and not statistically significant (coef= $0.0001, p=0.472, n=553)$. 
Figure 5: Difference in Willing to Take Risk Over Time.

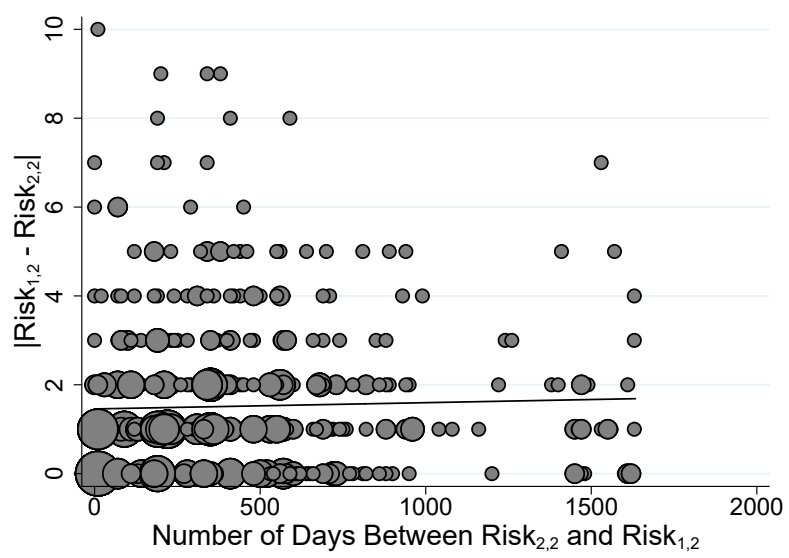

The solid lines is the fitted regression line. Dot sizes indicate the proportion of responses.

\subsubsection{Risk Measured with Real Stakes}

We have shown that AMT respondents provide consistent responses, but this does not necessarily mean the data is of high quality or economically meaningful. Consistent responses could be the result of careful consideration or a basic decision rule - for example, always answer the middle option. We now show that the data AMT workers provide is economically meaningful. We do so by showing that subjective risk preferences correlate in the expected direction with workers' decisions in a simple real stakes task: an incentivized lottery experiment (Johnson and Webb, 2016; Gibson and Johnson, 2018). ${ }^{11}$

In the experiment, workers are given a set of 20 lotteries (shown in Table 2) that vary in the probability they will be successful and the payoff that will be paid if the lottery turns out to be successful. Lotteries that are riskier (i.e., lower in index number) have a higher payoff (if successful) while lotteries that are safer (i.e., higher in index number)

\footnotetext{
${ }^{11}$ Note here we are focusing on the control treatment of Johnson and Webb (2016) that had workers select a single lottery rather than a bundle of lotteries. Gibson and Johnson (2018) had workers only select a single lottery.
} 
have a lower payoff (if successful). ${ }^{12}$ After being shown the possible lotteries that they can select, and each lottery's expected value, workers are asked to select the lottery that they wish to play for real stakes. The advantage of this simple risk task compared to some others available is that the measure does not conflate risk preference and math ability as is the case with some more complex measures, which makes it particularly suitable for the environment and population.

The stakes of the experiment are quite low relative to laboratory experiments. Workers, on average, earned about $\$ 1.15$ for their decisions. 122 workers completed the lottery experiment. The average subjective willingness to take risk of workers, taken at the time of the incentivized experiment is 4.76 . The correlation between these two variables is -0.332 and is statistically significant $(p=0.0002)$. The average index number of the lottery selected by these workers is 11.75 which is statistically significantly greater than the index number of the safer of two lotteries that are expected utility maximizing (lottery 11 in Table 2) assuming risk neutral preferences (t-test: $\mathrm{p}=0.039)$. Overall, roughly $67 \%$ of subjects selected a lottery that is consistent with some degree of risk averse preferences. Of subjects who completed the lottery experiment and a prior experiment in which they were asked to report their general willingness to take risk, this figure rises to approximately $76 \%$.

In both Johnson and Webb (2016) and Gibson and Johnson (2018) workers also reported their general willingness to take risk. 122 workers participated in either the control treatment of Johnson and Webb (2016) ( $n=47)$ or Gibson and Johnson (2018) $(n=75)$. We now demonstrate that workers' subjective willingness to take risk correlates with their lottery selections. We do so in two ways in Table 3's Tobit models. ${ }^{13}$ In Models 1 and 2, both measures are taken at the same point in time. In Models 3 and 4, we use only the

\footnotetext{
${ }^{12}$ In the actual experiment, lotteries are indexed by a letter of the alphabet rather than number.

${ }^{13}$ Similar results (in terms of significance and direction) are observed in all alternative models considered (i.e., OLS, ordered probit, and poisson).
} 
Table 2: Lotteries Used in Real Stakes Task

\begin{tabular}{cccccc}
\hline Lottery & Prob. & Prize & E.V. & Obs $_{1}$ & Obs $_{2}$ \\
\hline \hline 1 & 0.05 & $\$ 5.00$ & $\$ 0.25$ & 9 & 2 \\
2 & 0.1 & $\$ 4.75$ & $\$ 0.48$ & 0 & 0 \\
3 & 0.15 & $\$ 4.50$ & $\$ 0.68$ & 3 & 1 \\
4 & 0.2 & $\$ 4.25$ & $\$ 0.85$ & 0 & 0 \\
5 & 0.25 & $\$ 4.00$ & $\$ 1.00$ & 3 & 0 \\
6 & 0.3 & $\$ 3.75$ & $\$ 1.13$ & 0 & 0 \\
7 & 0.35 & $\$ 3.50$ & $\$ 1.23$ & 4 & 1 \\
8 & 0.4 & $\$ 3.25$ & $\$ 1.30$ & 1 & 0 \\
9 & 0.45 & $\$ 3.00$ & $\$ 1.35$ & 5 & 2 \\
10 & 0.5 & $\$ 2.75$ & $\$ 1.38$ & 15 & 2 \\
11 & 0.55 & $\$ 2.50$ & $\$ 1.38$ & 14 & 1 \\
12 & 0.6 & $\$ 2.25$ & $\$ 1.35$ & 8 & 7 \\
13 & 0.65 & $\$ 2.00$ & $\$ 1.30$ & 14 & 5 \\
14 & 0.7 & $\$ 1.75$ & $\$ 1.23$ & 9 & 2 \\
15 & 0.75 & $\$ 1.50$ & $\$ 1.13$ & 12 & 5 \\
16 & 0.8 & $\$ 1.25$ & $\$ 1.00$ & 8 & 1 \\
17 & 0.85 & $\$ 1.00$ & $\$ 0.85$ & 9 & 4 \\
18 & 0.9 & $\$ 0.75$ & $\$ 0.68$ & 4 & 1 \\
19 & 0.95 & $\$ 0.50$ & $\$ 0.48$ & 2 & 0 \\
20 & 1 & $\$ 0.25$ & $\$ 0.25$ & 2 & 0 \\
\hline
\end{tabular}

Prob. is the probability the lottery will favorable to the subject, Prize is the amount won if the lottery is favorable, and E.V. is the expected value of the lottery. Obs $s_{1}$ is the number of subjects who selected a given lottery. Obs ${ }_{2}$ is the number of subjects who selected a given lottery and completed a prior experiment in which they were asked to report their general willingness to take risk. 
Table 3: Subjective Risk Preferences and Risky Decision Making in a Real Stakes Task

\begin{tabular}{|c|c|c|c|c|c|c|c|c|}
\hline & \multicolumn{2}{|c|}{ Model 1} & \multicolumn{2}{|c|}{ Model 2} & \multicolumn{2}{|c|}{ Model 3} & \multicolumn{2}{|c|}{ Model 4} \\
\hline & Coef. & S.E. & Coef. & S.E. & Coef. & S.E. & Coef. & S.E. \\
\hline Contemporaneous Risk & -0.579 & 0.151 & -0.562 & 0.175 & & & & \\
\hline 1st Risk Response & & & & & -0.733 & 0.229 & -0.800 & 0.619 \\
\hline Days Since Response & & & & & 0.003 & 0.003 & 0.002 & 0.006 \\
\hline Days X 1st Response & & & & & & & 0.000 & 0.001 \\
\hline Male & & & 1.452 & 0.922 & & & & \\
\hline Age & & & 0.041 & 0.037 & & & & \\
\hline Impulsivity & & & -.003 & 0.042 & & & & \\
\hline Constant & 14.404 & 0.835 & 12.319 & 3.104 & 14.333 & 2.294 & 14.678 & 3.751 \\
\hline Obs & 12 & & 11 & & 3 & & 3 & \\
\hline $\mathrm{R}^{2}$ & 0.0 & & 0.0 & & 0.0 & & & \\
\hline LL & 9 & & $\varepsilon$ & & 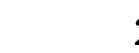 & & & \\
\hline UL & 2 & & 2 & & ( & & ( & \\
\hline
\end{tabular}

Tobit models. The dependent variable is the index number of lottery selected: larger values indicate less risky choices. $L L(U L)$ indicates the number of workers who selected lottery 1(20).

34 respondents who participated in more than one study. Moreover, instead of using their response to the subjective risk preference question from the same study as the lottery experiment, we use their subjective risk preference response from the first study in which they participated. ${ }^{14}$ This allows us to determine if survey responses from months (even years!) earlier are related to their real stakes behavior. The average gap, in days, between workers' first reported willingness to take risk and the lottery experiment is 521 days - more than a year. ${ }^{15}$ So these older measures are quite old relative to other studies that tend to use a 1-month reliability. Consequently, one could think of these measures as a lower bound in terms of relevancy as they correspond to an individual's willingness to take risk in the past.

\footnotetext{
${ }^{14}$ We do not use control variables in these models because of the smaller sample size.

${ }^{15}$ Roughly, $35 \%$ of subjects who completed the lottery experiment and a prior experiment in which they were asked to report their willingness to take risk completed both experiments within a year. $20 \%$ of subjects completed the lottery experiment more than 2 years after the first experiment in which they were asked to report their willingness to take risk.
} 
The subjective risk variable is measured with larger values indicating a greater willingness to take risk. At the same time, the riskier lottery choices are lower in index number. Therefore, since we expect subjective risk preferences to correlate with decisions made when there are real stakes, we expect to observe an inverse correlation between workers' response to the risk question and the lottery selected. This is exactly what is observed in Model 1 and Model 2 of Table 3. This suggests that the responses to the risk measure are not only consistent, but are economically meaningful. Hence, the data acquired via AMT worker responses are, on average, high quality measures.

In Models 3 and 4, we go a step further. First, as Model 3 shows, the same expected negative correlation holds - even if the subjective response was from an earlier time point. Second, as Model 4 shows, the size of correlation does not differ as the number of days since the first subjective response increases. We demonstrate this by including an interaction effect between the subjective response and the days since the response was given (Figure 6).

As Figure 6 shows, the marginal effect of subjective risk preferences on an individual's lottery choice is always around -0.7 . The relationship is statistically significant at the .05 level for responses given up to 2 years prior. After that point, we simply do not have enough observations to show the correlation with any confidence.

Naturally, it may be that the statistically significant relationship between subjective risk preferences and decisions made in the incentivized lottery experiment is being driven only by workers who participated in more than one experiment. This would be troublesome because it could suggest that only the decisions made by workers who participate in more than one experiment are economically relevant. Given that workers who participate in more than one experiment tend to be older, less willing take risk, and less impulsive this seems like a reasonable possibility. To explore whether or not this is the case, we reestimate Models 1 and 2 from Table 3 using data from workers who participated in one 
Figure 6: Marginal Effect of Willingness to Take Risk as Number of Days Since 1st Response Increases.

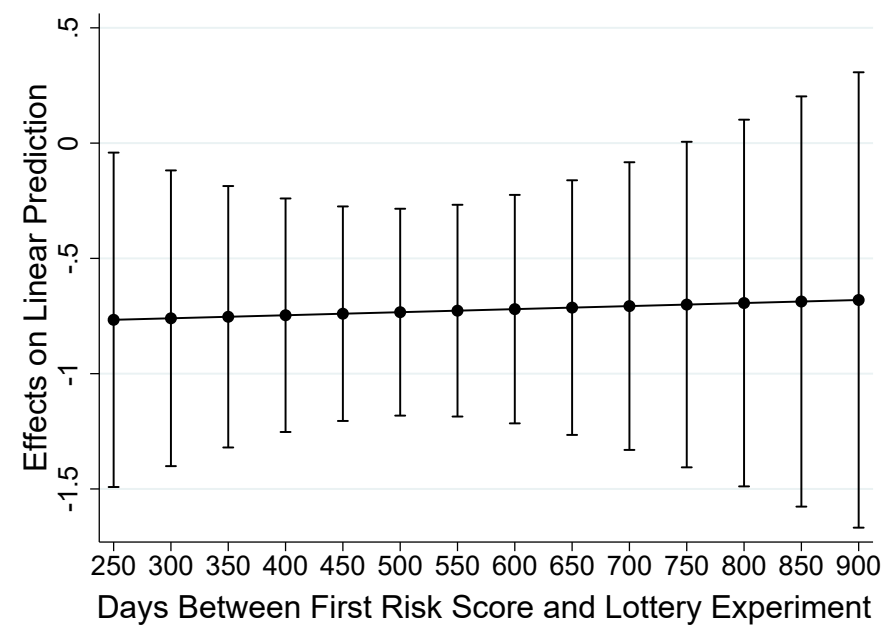

Marginal effect estimated from Model 4 in Table 3. Bars represent 95\% confidence intervals.

experiment $(\mathrm{EXP}=1)$ and workers who participate in more than one experiment $(\mathrm{EXP}>1)$. These results are presented in Table 4.

The results presented in Table 4 suggest that the subjective risk preferences of workers who participate in only one experiment predict risky decision making in the real stakes experiment. Further, coefficients in the models that use data from workers who completed only a single experiment are in the same ballpark as counterparts presented in Table 3 as well as models that use data from workers who completed more than one experiment.

In all, the results in this section are an important indication that AMT workers give not only consistent responses, but responses that map onto actual behavior. Further, because the responses are consistent, it does not matter when the response was recorded. Responses taken several months prior are just as good at predicting risky behavior in a real stakes task as responses taken at the same time. This suggests that, on average, AMT workers provide quality data, at least for the questions we asked respondents. 
Table 4: Subjective Risk Preferences and Risky Decision Making in a Real Stakes Task (Group 1 vs Group 2)

\begin{tabular}{|c|c|c|c|c|c|c|c|c|}
\hline & \multicolumn{2}{|c|}{$\begin{array}{c}\text { Model } 1 \\
\text { EXP }=1\end{array}$} & \multicolumn{2}{|c|}{$\begin{array}{c}\text { Model } 2 \\
\text { EXP>1 }\end{array}$} & \multicolumn{2}{|c|}{$\begin{array}{c}\text { Model } 3 \\
\text { EXP }=1\end{array}$} & \multicolumn{2}{|c|}{$\begin{array}{c}\text { Model } 4 \\
\text { EXP }>1\end{array}$} \\
\hline & Coef. & S.E & Coef. & S.E & Coef. & S.E & Coef. & S.E \\
\hline Contemporaneous Risk & -0.573 & 0.192 & -0.605 & 0.242 & -0.493 & 0.25 & -0.588 & 0.245 \\
\hline Male & & & & & 1.077 & 1.208 & 2.175 & 1.324 \\
\hline Age & & & & & 0.006 & 0.046 & 0.096 & 0.053 \\
\hline Impulsivity & & & & & -0.059 & 0.06 & 0.076 & 0.06 \\
\hline Constant & 14.756 & 1.093 & 14.025 & 1.291 & 17.426 & 3.349 & 4.765 & 5.495 \\
\hline Obs & \multicolumn{2}{|c|}{69} & \multicolumn{2}{|c|}{53} & \multicolumn{2}{|c|}{66} & \multicolumn{2}{|c|}{53} \\
\hline $\mathrm{R}^{2}$ & \multicolumn{2}{|c|}{0.0211} & \multicolumn{2}{|c|}{0.0194} & \multicolumn{2}{|c|}{0.0257} & \multicolumn{2}{|c|}{0.0393} \\
\hline LL & \multicolumn{2}{|c|}{5} & \multicolumn{2}{|c|}{4} & \multirow{2}{*}{\multicolumn{2}{|c|}{4}} & \multicolumn{2}{|c|}{4} \\
\hline UL & \multicolumn{2}{|c|}{1} & \multicolumn{2}{|c|}{1} & & & \multicolumn{2}{|c|}{1} \\
\hline
\end{tabular}

Tobit models. The dependent variable is the index number of lottery selected: larger values indicate less risky choices. $L L(U L)$ indicates the number of workers who selected lottery 1(20).

\section{Discussion and Conclusion}

Critics of studies using Amazon Mechanical Turk question the validity of studies using the platform for a wide variety of reasons. Many of these criticisms are valid. Namely, experiments involving an element of social interaction or those that require specific subject pools/samples are probably not best suited for the platform. However, in many experiments, these types of criticism are not applicable. Therefore, the primary concerns become those related to consistency and economic relevancy of workers' responses. We show that workers on Amazon Mechanical Turk consistently report their basic demographics, subjective risk preferences, and impulsivity. Further, their responses are economically relevant in, at the very least, a basic lottery experiment. Subjective willingness to take risk is significantly correlated with behavior in an incentivized lottery experiment and in the direction one would expect. In sum, the results suggest the quality of data obtained via AMT is not significantly harmed by the lack of control over the conditions under which the responses 
are recorded.

Researchers need to, however, use Amazon Mechanical Turk with care. As Arechar et al. (2017) shows, the population completing tasks on Amazon Mechanical Turk tends to be more male during the weekdays and the studies used to generate the data set that is analyzed here support this finding. Researchers using AMT should provide the time the HIT was posted along with any observed differences in their samples from ongoing large scale projects. Further, while the population of workers is generally more representative of the US population than typical university subject pools, there are still significant differences between the worker population and US population. Researchers need to take these differences seriously before making external validity claims. In terms of future steps, normatively, research using AMT is lacking in standardization. Unlike the lab, there are few established norms for conducting research on AMT or online, generally. A consensus of best practices (e.g., pay and reasons for blocking workers) needs to be reached for comparisons across studies to be meaningful. Such standardization could also foster increased experimental control.

To close, there are three caveats regarding the results presented in this manuscript. First, this paper is not about the overall demographics of the AMT worker population. Worker demographics vary across the day and week and there is evidence of long term trends in changing demographics. Given that the experiments were posted during relatively consistent times of day and over a long period of time, there is no reason to believe that the demographics presented will match the demographics of today's AMT worker population. Indeed, they do not. Second, this paper is not about identifying the inter-temporal correlation of various worker characteristics and demographics under the most controlled conditions allowed in the environment. The experiments from which we include data vary widely and the order of the measures taken in the experiments do as well. Further, we try to keep as many observations as possible. This means that we include data from workers who 
provided inconsistent answers, did not complete the experiment, or failed an English comprehension/attention check question. ${ }^{16}$ Third, it is well-known that the population of AMT workers may not be suitable for all research questions. While it is true that, demographically, AMT workers are significantly more varied than university subject pools (Ipeirotis, 2010; Buhrmester et al., 2011; Behrend et al., 2011), the AMT population is not representative of the US population as a whole. American workers on AMT generally have a lower reported income than the overall population of the US (c.f., Paolacci et al., 2010; Berinsky et al., 2012; Levay et al., 2016), are more likely to report to be unemployed (e.g., Ipeirotis, 2010; Goodman et al., 2016), younger, and are more ideologically liberal (Berinsky et al., 2012). ${ }^{17}$ Thus, this paper is not arguing that AMT is a suitable tool for all research questions. Instead, as we have shown, the purpose of this paper is to demonstrate that even in inconsistent settings, with low stakes, in an uncontrolled environment, with some of the worst workers possible, workers on AMT can provide consistent and economically meaningful data.

\footnotetext{
${ }^{16}$ So in some sense, the data analyzed in this study is the experimentalist's worst nightmare.

${ }^{17}$ However, AMT workers are fairly similar to samples created using other online survey platforms (Huff and Tingley, 2015).
} 


\section{References}

Arechar, Antonio A, Gordon T Kraft-Todd, and David G Rand (2017) 'Turking Overtime: How Participant Characteristics and Behavior Vary Over Time and Day on Amazon Mechanical Turk.' Journal of the Economic Science Association 3(1), 1-11

Behrend, Tara S, David J Sharek, Adam W Meade, and Eric N Wiebe (2011) 'The Viability of Crowdsourcing for Survey Research.' Behavior research methods 43(3), 800

Benjamini, Yoav, and Yosef Hochberg (1995) 'Controlling the False Discovery Rate: A Practical and Powerful Approach to Multiple Testing.' Journal of the Royal Statistical Society, Series B (Methodological) 57(1), 289-300

Berinsky, Adam J, Gregory A Huber, and Gabriel S Lenz (2012) 'Evaluating Online Labor Markets for Experimental Research: Amazon.com's Mechanical Turk.' Political Analysis 20(3), 351-368.

Buhrmester, Michael, Tracy Kwang, and Samuel D Gosling (2011) 'Amazon's Mechanical Turk: A New Source of Inexpensive, Yet High-Quality, Data?' Perspectives on Psychological Science 6(1), 3-5

Carlin, Ryan E., and Gregory J. Love (2013) 'The Politics of Interpersonal Trust and Reciprocity: An Experimental Approach.' Political Behavior 35(1), 43-63

Clifford, Scott (2014) 'Linking issue stances and trait inferences: a theory of moral exemplification.' The Journal of Politics 76(3), 698-710

Clifford, Scott, and Ben Gaskins (2016) 'Trust Me, I Believe in God: Candidate Religiousness as a Signal of Trustworthiness.' American Politics Research 44(6), 1066-1097

Converse, Philip E. 'Information flow and the stability of partisan attitudes.' Public Opinion Quarterly 26(4), 578-599 
Dave, Chetan, Catherine C. Eckel, Cathleen A. Johnson, and Christian Rojas (2010) 'Eliciting Risk Preferences: When is Simple Better?' Journal of Risk and Uncertainty 41(3), 219243

Del Ponte, Alessandro, Andrew W. Delton, Reuben Kline, and Nicholas A. Seltzer (2017) 'Passing It Along: Experiments on Creating the Negative Externalities of Climate Change.' Journal of Politics 79(4), 1444-1448

Dohmen, Thomas, Armin Falk, David Huffman, Uwe Sunde, Jürgen Schupp, and Gert G Wagner (2011) 'Individual Risk Attitudes: Measurement, Determinants, and Behavioral Consequences.' Journal of the European Economic Association 9(3), 522-550.

Farrington, David P. (1998) 'Predictors, Causes, and Correlates of Male Youth Violence.' Crime and Justice 24, 421-475

Flores, Andrew R, Taylor NT Brown, and Jody Herman (2016) Race and Ethnicity of Adults Who Identify as Transgender in the United States (Williams Institute, UCLA School of Law)

Fowler, James H., and Cindy D. Kam (2007) 'Beyond the Self: Social Identity, Altruism, and Political Participation.' The Journal of Politics 69(3), 813-827

Gibson, John, and David Johnson (2018) 'Assessing the Stability of Risk Preferences Online.' Technical Report, University of Central Missouri

Goodman, Joseph K., Cynthia E. Cryder, and Amar Cheema (2013) 'Data Collection in a Flat World: The Strengths and Weaknesses of Mechanical Turk Samples.' Journal of Behavioral Decision Making 26(3), 213-224

Goodman, William K, Ashley M Geiger, and Jutta M Wolf (2016) 'Differential Links between Leisure Activities and Depressive Symptoms in Unemployed Individuals.' Journal of Clinical Psychology 72(1), 70-78. 
Hatemi, Peter K., John R. Alford, John R. Hibbing, Nicholas G. Martin, and Lindon J. Eaves (2009) 'Is There a 'Party' in Your Genes?' Political Psychology (3), 584-600

Holt, Charles A, and Susan K Laury (2002) 'Risk Aversion and Incentive Effects.' American economic review 92(5), 1644-1655.

Horton, John J, David G Rand, and Richard J Zeckhauser (2011) 'The Online Laboratory: Conducting Experiments in a Real Labor Market.' Experimental Economics 14(3), 399425

Huff, Connor, and Dustin Tingley (2015) “"Who are These People?” Evaluating the Demographic Characteristics and Political Preferences of MTurk Survey Respondents.' Research \& Politics 2(3), 2053168015604648

Ipeirotis, Panagiotis G (2010) 'Demographics of Mechanical turk.'

Johnson, David B, and Matthew D Webb (2016) 'Decision Making with Risky, Rival Outcomes: Theory and Evidence.' Technical Report, Carleton University, Department of Economics

Krupnikov, Yanna, and Adam Seth Levine (2014) 'Cross-Sample Comparisons and External Validity.' Journal of Experimental Political Science 1(1), 59-80

Levay, Kevin E, Jeremy Freese, and James N Druckman (2016) 'The Demographic and Political Composition of Mechanical Turk Samples.' SAGE Open 6(1), 2158244016636433.

Lopez, Jesse, and D. Sunshine Hillygus (2018) 'Why So Serious?: Survey Trolls and Misinformation.' Available at SSRN: https://ssrn.com/abstract $=3131087$ or http://dx.doi.org/10.2139/ssrn.3131087

McAdams, Dan P., Kathrin J. Hanek, and Joseph G. Dadabo (2013) 'Themes of Self- 
Regulation and Self-Exploration in the Life Stories of Religious American Conservatives and Liberals.' Political Pyschology 34(2), 201-219

McDermott, Rose, Chris Dawes, Elizabeth Prom-Wormley, Lindon Eaves, and Peter K. Hatemi (2013) 'MAOA and Aggression: A Gene-Environment Interaction in Two Populations.' The Journal of Conflict Resolution 57(6), 1043-1064

Milita, Kerri, Elizabeth N. Simas, John Barry Ryan, and Yanna Krupnikov (2017) 'The Effects of Ambiguous Rhetoric in Congressional Elections.' Electoral Studies 46(April), 48-63

Mullinix, Kevin J., Thomas J. Leeper, James N. Druckman, and Jeremy Freese (2015) 'The Generalizability of Survey Experiments.' Journal of Experimental Political Science 2(2), 109-138

Paolacci, Gabriele, Jesse Chandler, and Panagiotis G Ipeirotis (2010) 'Running Experiments on Amazon Mechanical Turk.'

Richter, David, Julia Roher, Maria Metzing, Wiebke Nestler, Michael Weinhardt, and Jürgen Schupp (2017) 'SOEP Scales Manual (updated for SOEP-Core v32. 1).' Technical Report, SOEP Survey Papers

Stanford, Matthew S, Charles W Mathias, Donald M Dougherty, Sarah L Lake, Nathaniel E Anderson, and Jim H Patton (2009) 'Fifty Years of the Barratt Impulsiveness Scale: An Update and Review.' Personality and Individual Differences 47(5), 385-395

Verkoeijen, Peter P. J. L., and Samantha Bouwmeester (2014) 'Does Intuition Cause Cooperation?' PloS ONE. https://doi.org/10.1371/journal.pone.0096654

Zaller, John (1992) The Nature and Origins of Mass Opinion (New York: Cambridge University Press) 


\section{Appendix for: \\ Amazon Mechanical Turk Workers Can Provide Consistent and Economically Meaningful Data}

June 28, 2018

\section{Day of the Week}

Figure A.1 presents the percentage of workers who report to be male, their average age, average willingness to take risk, and average Impulsiveness Test scores by the day of the week.

Figure A.1: Gender, Age, Risk, and IMP by Day of Week
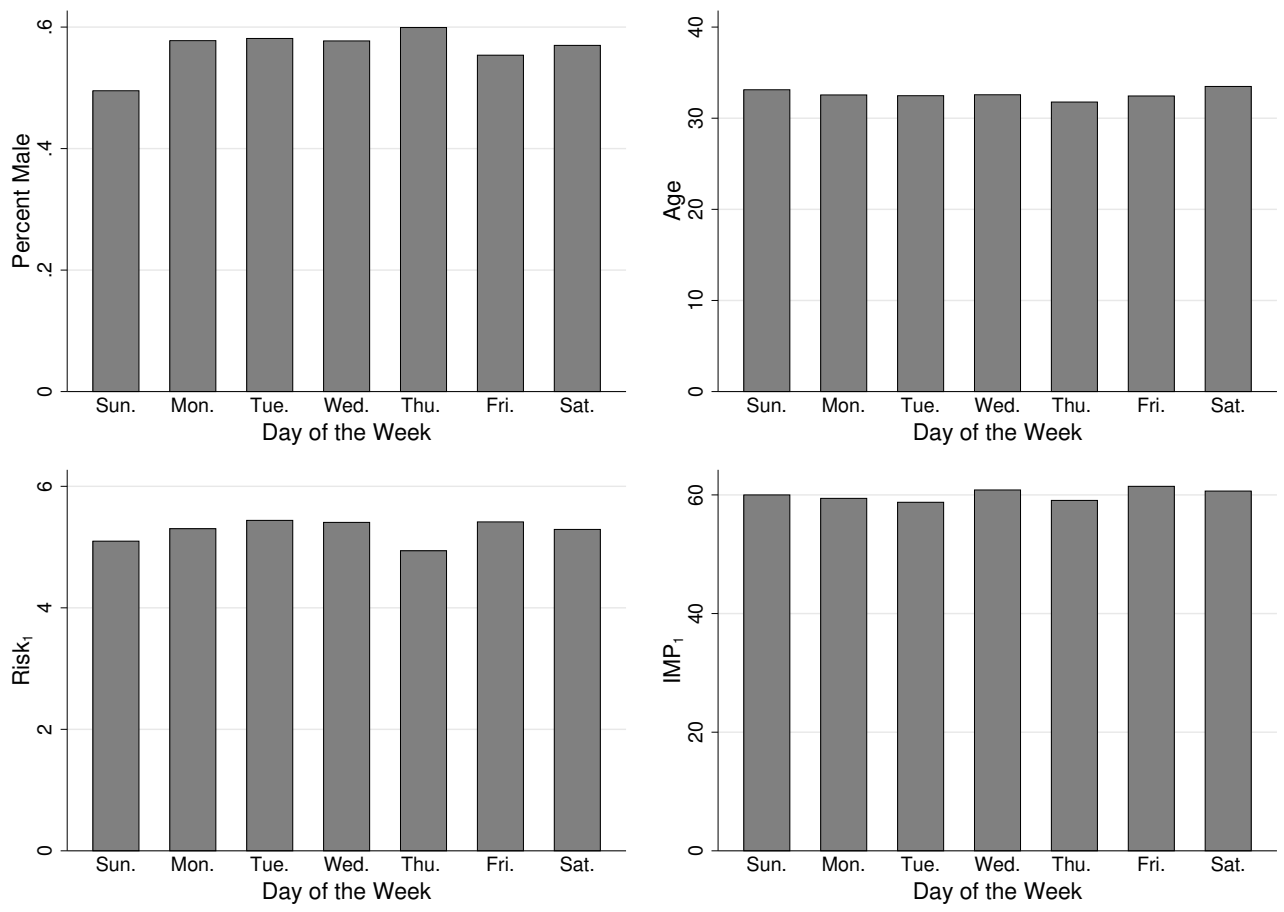

Notes: First/only reported gender, age, willingness to take risk, and Barratt Impulsivity Test scores by day of week. 


\section{Determinants of the Number of Experiments Completed}

Table B.1 presents the primary Pearson correlations of the variables of interest and the number of experiments the worker completed (Completions). The correlations, in terms of characteristics and the number of experiments completed, generally fall into the direction one would expect: workers who are more willing to take risk completed fewer experiments and tend to be more impulsive.

Table B.1: Correlations of Main Variables

\begin{tabular}{ccccc}
\hline \hline & Completions & Male $_{1}$ & $\mathrm{Age}_{1}$ & Risk $_{1}$ \\
\hline \hline Male $_{1}$ & 0.0508 & & & \\
& $(0.001)$ & & & \\
$\mathrm{Age}_{1}$ & 0.0367 & -0.1568 & & \\
& $(0.051)$ & $(<0.001)$ & & \\
Risk $_{1}$ & -0.0596 & 0.1632 & -0.1287 & \\
& $(<0.001)$ & $(<0.001)$ & $(<0.001)$ & \\
$\mathrm{IMP}_{1}$ & -0.0819 & 0.0505 & -0.1287 & 0.2155 \\
& $(<0.001)$ & $(0.009)$ & $(<0.001)$ & $(<0.001)$ \\
\hline
\end{tabular}

Notes: Correlations of primary variables of interest and the number of experiments completed. P-values of correlations indicated in parenthesis. 


\section{Gender Differences}

There are some interesting gender differences to report. These differences are summarized in Table C.1. First, when examining all workers' first/only responses, we find that males are significantly more impulsive and more willing to take risk. While the significant difference in willingness to take risk is consistent with prior studies (c.f., Dohmen et al., 2011) the difference in impulsiveness is not. However, our reported difference is small in magnitude and consistent with the magnitude of the difference reported in Stanford et al. (2009) that was not found to be statistically significant (62.8 vs 62.1). Second, females are significantly older.

The difference in average ages across genders is important to highlight because previous literature has identified an inverse relationship between impulsiveness and age Spinella (c.f., 2007). Thus, given that females in the sample are significantly older it is reasonable to expect them to be less impulsive. To further address the impulsiveness discrepancy, we use OLS to estimate workers' first/only impulsiveness test score (Obs $=1,377$ ) using first reported gender and age as independent variables. The OLS results support the above proposition as the coefficient on age is found to be statistically significant (coef $=-0.151$, $p<0.001$ ) while gender ( 1 if male; 0 if female) is not (coef $=0.079, p=0.904$ ). Finally, when examining workers' second responses, the gender difference in impulsiveness is no longer significant while the significant differences in age and risk remains. These results are available upon request.

Table C.1: Gender Differences

\begin{tabular}{cccc}
\hline \hline \multicolumn{4}{c}{ First Response (All workers) } \\
& IMP & Risk & Age \\
\hline \hline Male & 60.533 & 5.678 & 31.230 \\
Female & 59.346 & 4.779 & 34.401 \\
\hline t-test: & 0.009 & $<0.001$ & $<0.001$ \\
u-test: & 0.004 & $<0.001$ & $<0.001$ \\
\hline \hline \multicolumn{4}{c}{ Second Responses } \\
& IMP & Risk & Age \\
\hline \hline Male & 58.365 & 5.259 & 32.959 \\
Female & 58.260 & 4.338 & 35.792 \\
\hline t-test: & 0.971 & $<0.001$ & 0.004 \\
u-test: & 0.661 & $<0.001$ & 0.007 \\
\hline
\end{tabular}

Notes: Gender differences in Impulsiveness Test scores, willingness to take risk, and age. p-values of tests of significance shown below averages. 


\section{Consistency of Individual Test Questions}

Naturally however, the consistency in Impulsiveness Test scores may be due to how the test scores are calculated. For example, two different Impulsiveness Test scores might be similar but the worker could have answered individual questions in such a manner that the aggregate test scores did not change much. Further, because the test scores are an aggregate of 30 questions, workers could answer each of the questions randomly and have test scores that are not significantly different. To rule this possibility out, in Table D.1, we present the average first and last response for each of the test questions in the Impulsiveness Test as well as the correlation of answers. Of the 30 questions, two of the test questions have a significant difference in the first and last response. However, the significant differences in average responses are generally quite small. Further, the inter-temporal correlation of workers' responses to each of the questions are positive and significant. This result suggests that not only are Impulsiveness Test scores consistent but also the test questions themselves. 
Table D.1: Differences in Each Impulsiveness Test Question

\begin{tabular}{|c|c|c|c|c|c|c|}
\hline & $\mathrm{IMPQ}_{1,2}$ & $\mathrm{IMPQ}_{2,2}$ & Diff & $p$ & B.H. $p$ & $r$ \\
\hline I plan tasks carefully. & 3.054 & 3.135 & -0.081 & 0.028 & 0.757 & 0.493 \\
\hline I do things without thinking. & 1.611 & 1.616 & -0.005 & 0.896 & 1.000 & 0.481 \\
\hline I make-up my mind quickly. & 2.377 & 2.374 & 0.002 & 0.953 & 1.000 & 0.459 \\
\hline I am happy-go-lucky. & 2.328 & 2.328 & 0 & 1.000 & 1.000 & 0.672 \\
\hline I don't pay attention. & 1.387 & 1.397 & -0.01 & 0.778 & 1.000 & 0.444 \\
\hline I have racing thoughts. & 1.958 & 1.958 & 0 & 1.000 & 1.000 & 0.471 \\
\hline I plan trips well ahead of time. & 3.039 & 3.086 & -0.047 & 0.247 & 0.926 & 0.539 \\
\hline I am self controlled. & 3.064 & 3.069 & -0.005 & 0.898 & 1.000 & 0.484 \\
\hline I concentrate easily. & 2.966 & 3.005 & -0.039 & 0.292 & 0.9733 & 0.579 \\
\hline I save regularly. & 2.766 & 2.8 & -0.034 & 0.397 & 1.000 & 0.651 \\
\hline I squirm at plays or lectures. & 1.988 & 2.057 & -0.069 & 0.101 & 0.758 & 0.6 \\
\hline I am a careful thinker. & 3.128 & 3.153 & -0.025 & 0.516 & 1.000 & 0.49 \\
\hline I plan for job security. & 2.761 & 2.781 & -0.02 & 0.637 & 1.000 & 0.599 \\
\hline I say things without thinking. & 1.707 & 1.707 & 0 & 1.000 & 1.000 & 0.46 \\
\hline I like to think about complex problems. & 2.736 & 2.736 & 0 & 1.000 & 1.000 & 0.603 \\
\hline I change jobs. & 1.756 & 1.707 & 0.049 & 0.208 & 0.891 & 0.493 \\
\hline I act on impulse. & 1.8 & 1.8 & 0 & 1.000 & 1.000 & 0.435 \\
\hline I get easily bored when solving thought problems. & 1.862 & 1.865 & -0.002 & 0.954 & 1.000 & 0.439 \\
\hline I act on the spur of the moment. & 1.877 & 1.872 & 0.005 & 0.902 & 1.000 & 0.467 \\
\hline I am a steady thinker. & 3.012 & 3.079 & -0.067 & 0.077 & 0.758 & 0.523 \\
\hline I change residences. & 1.638 & 1.65 & -0.012 & 0.745 & 1.000 & 0.505 \\
\hline I buy things on impulse. & 1.842 & 1.842 & 0 & 1.000 & 1.000 & 0.475 \\
\hline I can only think about one thing at a time. & 1.906 & 1.906 & 0 & 1.000 & 1.000 & 0.519 \\
\hline I change hobbies. & 1.84 & 1.818 & 0.022 & 0.574 & 1.000 & 0.502 \\
\hline I spend or charge more than I earn. & 1.562 & 1.554 & 0.007 & 0.838 & 1.000 & 0.585 \\
\hline I often have extraneous thoughts when thinking. & 2.135 & 2.081 & 0.054 & 0.194 & 0.891 & 0.515 \\
\hline I am more interested in the present than the future. & 2.357 & 2.337 & 0.02 & 0.631 & 1.000 & 0.497 \\
\hline I am restless at the theatre or lectures. & 1.929 & 1.988 & -0.059 & 0.156 & 0.891 & 0.604 \\
\hline I like puzzles. & 2.951 & 2.879 & 0.071 & 0.072 & 0.758 & 0.616 \\
\hline I am future oriented. & 2.754 & 2.761 & -0.007 & 0.857 & 1.000 & 0.55 \\
\hline
\end{tabular}

Notes: First $\left(\mathrm{IMPQ}_{1,2}\right)$ and last $\left(\mathrm{IMPQ}_{2,2}\right)$ impulsiveness test question and difference in response. Column labeled " $p$ " indicates the p-value from paired t-tests, testing whether the average difference is statistically different. B.H. $p$ is the p-values following a correction for multiple comparisons (Benjamini and Hochberg, 1995). Column labeled " $r$ " indicates the Pearson correlation of responses. Obs $=406$. All correlations are significant (i.e., $p<0.01)$. 


\section{The Experiments}

In Table E.1, we present the eleven experiments that we used to generate the data set. A brief description of each of the experiments is given in the subsections below.

Table E.1: The Experiments

\begin{tabular}{|c|c|c|c|c|c|}
\hline & Age & Gender & Risk & IMP & Start Date \\
\hline $\begin{array}{c}\text { Study } 1 \\
(\text { Obs }=865)\end{array}$ & $\checkmark$ & $\checkmark$ & $\checkmark$ & & Sept 12, 2012 \\
\hline $\begin{array}{c}\text { Study } 2 \\
(\text { Obs }=235)\end{array}$ & $\checkmark$ & $\checkmark$ & & & Feb 17, 2014 \\
\hline $\begin{array}{c}\text { Study } 3 \\
(\mathrm{Obs}=485)\end{array}$ & $\checkmark$ & $\checkmark$ & $\sqrt{ }$ & $\checkmark$ & Mar 14, 2015 \\
\hline $\begin{array}{c}\text { Study } 4 \\
(\mathrm{Obs}=314)\end{array}$ & $\checkmark$ & $\checkmark$ & $\checkmark$ & $\checkmark$ & May 11, 2015 \\
\hline $\begin{array}{l}\text { Study } 5 * \\
(\text { Obs }=60)\end{array}$ & $\checkmark$ & $\checkmark$ & $\checkmark$ & & Feb 26, 2016 \\
\hline $\begin{array}{c}\text { Study 6* } \\
(\text { Obs }=504)\end{array}$ & $\checkmark$ & $\checkmark$ & $\checkmark$ & & Mar 16, 2016 \\
\hline $\begin{array}{c}\text { Study } 7 * \\
(\text { Obs }=250)\end{array}$ & $\checkmark$ & $\checkmark$ & & $\checkmark$ & Apr 26, 2016 \\
\hline $\begin{array}{c}\text { Study } 8 \\
(\text { Obs }=649)\end{array}$ & $\checkmark$ & $\checkmark$ & $\checkmark$ & $\checkmark$ & Jul 08, 2016 \\
\hline $\begin{array}{c}\text { Study } 9 \\
(\text { Obs }=970)\end{array}$ & & $\checkmark$ & $\checkmark$ & $\checkmark$ & Mar 23, 2017 \\
\hline $\begin{array}{c}\text { Study } 10 \\
(\text { Obs }=940)\end{array}$ & & $\checkmark$ & $\checkmark$ & $\checkmark$ & Nov 26, 2017 \\
\hline $\begin{array}{l}\text { Study } 11 \\
(\text { Obs=75) }\end{array}$ & $\checkmark$ & $\checkmark$ & $\checkmark$ & $\checkmark$ & Jan 17, 2018 \\
\hline
\end{tabular}

Notes: Experiments in the data set. Left most column indicates the authors of the $\mathrm{HIT} /$ study and the number of submissions (Obs). Middle four columns indicate the questions that are asked in the study. Final column indicates the first day a batch of the experiment was posted. "*”" indicates that the study was joint work with a student for a school project. All studies were approved by the IRB of the University the first author was affiliated with at the time of the study.

\subsection{Ambiguity and Performance Pay (Study 1)}

In the experiment, workers were asked to participate in one of two tasks: coding messages (Task A) from Charness and Dufwenberg (2006) or a simple transcription task (Task B). To code messages, workers had to read the message and classify the message using six possible 
categories. In the transcription task, workers were shown an image of a word and had to type the word that was shown into a text box. The experiment varied the information given to workers relating to how their bonuses were calculated if they selected the coding task and the amount they would be paid if they completed the transcription task. Workers reported their age, gender, and willingness to take risk in a survey that occurred prior to the main experiment. Workers on average earned about $\$ 0.60$ and spent about 15 minutes on the experiment.

\subsection{The Effect of Financial Goals and Incentives on Labor. An Experimental Test in a Real(ish) Labor Market (Study 2)}

In the experiment, workers were assigned into one of four treatments and completed a real effort task. Workers transcribed pieces of an instruction manual from a 1996 Oldsmobile Cutlass. Before seeing the treatment screen, workers completed five practice transcriptions, each paying 2 cents each. In the treatment assignment screen, which was shown after the practice period, workers read a short piece of text that assigned them to a treatment and gave them a wage rate. In the "Do Your Best" treatment, the text read "Working for us your goal is to just do your best and do as many sentences as you can" in the "goal" treatment, the text read "Working for us your goal is to make $\$ 2$." Above this information, workers were shown their wage rate that would be paid (2 Cents or 5 Cents). Workers were paid this amount for each transcription they completed. Workers reported their age and gender prior to the treatment assignment screen. Workers, on average, made a little more than $\$ 2$ dollars and spent about 30 minutes on the task. While workers in this study also completed the Barratt Impulsiveness Test after the experiment, one of the question responses had the same name as a different question. Thus, responses to this question were overwritten. Therefore, we do not use Impulsiveness test scores from this study.

\subsection{An Experimental Test of the No Safety Schools Theorem (Study 3)}

In the experiment presented in this paper, workers were asked to select a set of lotteries from a fixed set of lotteries and complete a survey. The experiment varied the number of lotteries the worker could select and the payment regime. The actual lotteries workers could select are found in Table E.2. In the first regime, workers were paid based upon the outcome of the lottery in their selected set that is most favorable to them and in the second regime they are paid based off of the outcome of one of the lotteries that was selected at random. The experiment took on average 21 minutes to complete. Workers on average earned \$2.33. While only 294 individuals participated in the treatments that are discussed in the version of the manuscript that is circulating as of May 21, 2018, an additional 192 workers participated in treatments that were not reported. Age and gender were collected

prior to the start of the main experiment. Impulsivity and willingness to take risk were collected after. 
Table E.2: Lotteries Used in the Experiments

\begin{tabular}{lllllllllllllllllllllll}
\hline \hline & $\mathrm{A}$ & $\mathrm{B}$ & $\mathrm{C}$ & $\mathrm{D}$ & $\mathrm{E}$ & $\mathrm{F}$ & $\mathrm{G}$ & $\mathrm{H}$ & $\mathrm{I}$ & $\mathrm{J}$ & $\mathrm{K}$ & $\mathrm{L}$ & $\mathrm{M}$ & $\mathrm{N}$ & $\mathrm{O}$ & $\mathrm{P}$ & $\mathrm{Q}$ & $\mathrm{R}$ & $\mathrm{S}$ & $\mathrm{T}$ \\
\hline \hline Prob & .05 & .10 & .15 & .20 & .25 & .30 & .35 & .40 & .45 & .50 & .55 & .60 & .65 & .70 & .75 & .80 & .85 & .90 & .95 & 1.00 \\
Prize & 5.00 & 4.75 & 4.50 & 4.25 & 4.00 & 3.75 & 3.50 & 3.25 & 3.00 & 2.75 & 2.50 & 2.25 & 2.00 & 1.75 & 1.50 & 1.25 & 1.00 & 0.75 & 0.50 & 0.25 \\
$\mathrm{EV}$ & 0.25 & 0.48 & 0.68 & 0.85 & 1.00 & 1.13 & 1.23 & 1.30 & 1.35 & 1.38 & 1.38 & 1.35 & 1.30 & 1.23 & 1.13 & 1.00 & 0.85 & 0.68 & 0.48 & 0.25 \\
\hline
\end{tabular}

Notes: Lotteries used in Study 3 and Study 11.

\subsection{Untitled Stress Experiment (Study 4)}

This experiment explored the effect of quickly shown images on productivity. Productivity was measured using a real effort task. Workers were assigned into one of three groups. In the treatment groups, after completing 4 real effort tasks, workers were shown either an image of a seal or Linda Blair (in full exorcist make-up). In the control group, workers were not shown any image. Age and gender were collected prior to the start of the main experiment. Impulsivity and willingness to take risk were collected after.

\subsection{Testing for Selection on AMT (Study 5)}

Workers who accepted the HIT were assigned into one of two treatments. In the first treatment, workers completed a survey on AMT. In the second treatment, workers completed the same survey but had to click a link that took them to the same survey that was hosted on Survey Monkey instead of AMT. The experiment paid \$1.50 and workers spent, on average, about 30 minutes on the experiment. Because workers who were assigned to the treatment that had them complete the survey on Survey Monkey did not have their Worker ID number attached to their answers, we us only workers who participated in the first treatment.

\subsection{The Effect of Differential Tuition on Choice of College Major (Study 6)}

This experiment explored how proposed increases in major-specific tuition rates influences peoples' decisions regarding changing their majors, transferring schools, and willingness to drop out of college entirely. The experiment did so using a "menu" style survey and a standard survey question. In each set of questions in the menu style treatments, workers answered 10 questions that asked "if their tuition was raised by X percent, would they switch majors?" - where $\mathrm{X}$ is $10,20, . .100$. In the "\% change" treatments (or standard survey question), workers were asked what is the minimum percent increase in their tuition that would cause them to switch majors. The experiment also varied whether the hypothetical increase in cost increased the cost of the student's major only or raised the price of tuition for all majors at their university. For participation, workers were paid 1 dollar. Workers were asked to report their age, gender, and willingness to take risk prior to the main experiment. 


\subsection{The Effect of Precision Pricing on Perceived Home Value (Study 7)}

This experiment explored the effect of "precision pricing" on the amount workers would be willing to bid on homes. In the experiment, workers were shown a set of three homes. The experiment varied the type of homes (low cost vs high cost) workers bid on $(110,000$ and 300,000 ) and the precision of the price (house value $+.05 \%,+0$, and $-.05 \%$ of the home's value). Workers were paid 1 dollar for participating and the experiment took on average 36 minutes. The survey, which collected workers' age, gender, and impulsivity, took place after the experiment.

\subsection{The Effect of Wage Inequality (Study 8)}

This experiment explored the interaction of pay and knowledge of others' pay on worker productivity. Workers in the experiment were paid either 2, 4, or 20 cents for each word they correctly coded and were truthfully told some other workers are paid 2, 4 or 20 cents for each word they correctly code. To identify wage effects, some workers were given no information regarding the wage rates of others. After completing the real effort portion of the experiment, workers completed the survey. Workers on average earned \$1.85 and took 32 minutes to complete the experiment. Age and gender was collected prior to the start of the experiment. Impulsivity and willingness to take risk was collected after.

\subsection{Should I Give up or Hold out? The Differential Impact of Debt on Wage Selectivity I (Study 9)}

In the experiment presented in this paper, workers participated in a two period experiment. In the first period workers were assigned a debt (that was randomly assigned) and given a "wage" offer. Workers then decided whether to reject or accept the wage offer. If the worker accepted the wage offer, the worker earned two times the offered wage (from working both periods) minus their assigned debt. If the wage offer was rejected, the worker was given a second wage offer and earned the second wage minus their assigned debt. If the worker ended the experiment with negative earnings, the worker earned nothing. On average, the experiment took 7.6 minutes to complete and paid $\$ 0.26$ in addition to a $\$ 0.25$ participation fee. Age, gender, risk, and impulsivity were all collected prior to the start of the experiment.

\subsection{Should I Give up or Hold out? The Differential Impact of Debt on Wage Selec- tivity II (Study 10)}

In the experiment, workers were assigned a debt and were given two minutes to accept a wage (which were randomly generated by the computer) and complete a real effort task that paid the accepted wage times the number of tasks they completed. Workers could reject as many wages as they wished knowing that if the product of their accepted wage and the number of tasks they completed was less than their debt, they would earn nothing. On average, the experiment took about 12 minutes to complete and paid \$0.31 in addition 
to a $\$ 0.25$ cents participation fee. Age, gender, risk, and impulsivity were all collected prior to the start of the experiment.

\subsection{The Economic Relevancy of Risk Preferences Elicited Online and With Low Stakes (Study 11)}

In the experiment presented in this paper, workers completed a set of surveys and four risk aversion tests with monetary incentives. On average, workers spent 18 and a half minutes on the experiment and earned \$4.39. Age and gender was collected prior to the start of the first two risk aversion tests (a standard Holt and Laury and a Holt and Laury with $\frac{1}{5}$ stakes - Holt and Laury (2002)). Risk and impulsivity was collected after completing the first two risk aversion tests but before the final two risk aversion tests (Gneezy and Potters, 1997; Johnson and Webb, 2016).

\section{References}

Benjamini, Yoav, and Yosef Hochberg (1995) 'Controlling the False Discovery Rate: A Practical and Powerful Approach to Multiple Testing.' Journal of the Royal Statistical Society, Series B (Methodological) 57(1), 289-300

Charness, Gary, and Martin Dufwenberg (2006) 'Promises and partnership.' Econometrica 74(6), 1579-1601

Dohmen, Thomas, Armin Falk, David Huffman, Uwe Sunde, Jürgen Schupp, and Gert G Wagner (2011) 'Individual Risk Attitudes: Measurement, Determinants, and Behavioral Consequences.' Journal of the European Economic Association 9(3), 522-550.

Gneezy, Uri, and Jan Potters (1997) 'An Experiment on Risk Taking and Evaluation Periods.' The Quarterly Journal of Economics 112(2), 631-645

Holt, Charles A, and Susan K Laury (2002) 'Risk Aversion and Incentive Effects.' American economic review 92(5), 1644-1655.

Johnson, David B, and Matthew D Webb (2016) 'Decision Making with Risky, Rival Outcomes: Theory and Evidence.' Technical Report, Carleton University, Department of Economics

Spinella, Marcello (2007) 'Normative Data and a Short Form of the Barratt Impulsiveness Scale.' International Journal of Neuroscience 117(3), 359-368

Stanford, Matthew S, Charles W Mathias, Donald M Dougherty, Sarah L Lake, Nathaniel E Anderson, and Jim H Patton (2009) 'Fifty Years of the Barratt Impulsiveness Scale: An Update and Review.' Personality and Individual Differences 47(5), 385-395 